\title{
Обзоры
}

(с) Коллектив авторов, 2020

УДК616-092

Воронков Н.С., Нарыжная Н.В., Маслов Л.Н.

\section{Роль киназ в реализации инфаркт-лимитирующего эффекта адаптации к гипоксии}

Научно-исследовательский институт кардиологии, Томский национальный исследовательский медицинский центр РАН, 634012, г. Томск, Россия, Киевская ул.,111а

\begin{abstract}
Цель обзора - анализ данных о роли киназ в кардиопротекторном эффекте адаптации к гипоксии. Установлено, что изоформы $\delta$ и $\varepsilon$ протеинкиназы С участвуют в кардиопротекторном эффекте адаптации к гипоксии. Показано, что хроническая гипоксия вызывает усиление экспрессии киназ СаМKII, p-ERK1/2, p-p38, p-Akt, гексокиназы-1, гексокиназы-2. Гипоксия усиливает транслокацию гексокиназы-2 в митохондрии. У животных, адаптированных к гипоксии, не удалось обнаружить увеличения экспрессии киназ ПКА, p-GSK3ß, AMPK и JNK. Представлены данные, указывающие на то, что киназы ERK1/2, MEK1/2 участвуют в кардиопротекторном эффекте адаптации к гипоксии. Гипертрофия миокарда, вызванная хронической гипоксией, связана с активацией Rho-киназы. Вопрос о роли PI3, Akt JNK, PKG, Rho-киназы, mTOR и р38 в защитном эффекте адаптации к гипоксии остается спорным.
\end{abstract}

Ключевые слова: сердце; адаптация; хроническая гипоксия; ишемия/реперфузия; киназы.

Для цитирования: Воронков Н.С., Нарыжная Н.В., Маслов Л.Н. Роль киназ в реализации инфаркт-лимитирующего эффекта адаптации к гипоксии. Патологическая физиология и экспериментальная терапия. 2020; 64(1): 128-134.

DOI: 10.25557/0031-2991.2020.01.128-134

Для корреспонденции: Маслов Леонид Николаевич, e-mail: maslov@cardio-tomsk.ru

Финансирование. Работа выполнена при поддержке Российского научного фонда, грант 16-15-10001. Раздел, посвященный ПКА и ПКG, выполнен в рамках государственного задания АААА-А15-115120910024-0.

Конфликт интересов. Авторы заявляют об отсутствии конфликта интересов.

Поступила 21.11.2019

Принята в печать 16.01 .2020

Опубликована 25.02.2020

Voronkov N.S., Naryzhnaya N.V., Maslov L.N.

\section{The role of kinases in the infarct-limiting effect of adaptation to hypoxia}

Cardiology Research Institute, Tomsk National Research Medical Center of the RAS,

Kievskaya Str. 111a, Tomsk 634012, Russia

The objective of this review was to analyze reports on the role of kinases in the cardioprotective effect of adaptation to hypoxia. It was established that the $\delta$ and $\varepsilon$ isoforms of protein kinase $C$ are involved in the cardioprotective effect of adaptation to hypoxia. Chronic hypoxia has been shown to increase expression of CaMKII, p-ERK1/2, p-p38, p-Akt, hexokinase-1, and hexokinase-2 kinases. Hypoxia enhances translocation of hexokinase-2 to mitochondria. In animals adapted to hypoxia, no increase in the expression of PKA, p-GSK3 $\beta$, AMPK, and JNK kinases was detected. The presented data indicate that ERK1/2 and MEK1/2 kinases are involved in the cardioprotective effect of adaptation to hypoxia. Myocardial hypertrophy induced by chronic hypoxia is associated with activation of Rho kinase. The role of PI3K, Akt JNK, PKG, Rho kinase, mTOR, and p38 kinase in the protective effect of adaptation to hypoxia is controversial.

Keywords: heart; adaptation; chronic hypoxia; ischemia/reperfusion; kinases.

For citation: Voronkov N.S., Naryzhnaya N.V., Maslov L.N. The role of kinases in the infarct-limiting effect of adaptation to hypoxia. Patologicheskaya Fiziologiya i Eksperimental'naya terapiya. Pathological physiology and experimental theraiya, Russian Journal). 2020; 64(1): 128-134. (in Russian).

DOI: $10.25557 / 0031-2991.2020 .01 .128-134$

For correspondence: Leonid N. Maslov, Professor, Head of Laboratory Experimental Cardiology, Cardiology Research Institute, Tomsk National Research Medical Center, Russian Academy of Sciences; Kievskaya st., 111A, 634012, Russia, e-mail: maslov@cardio-tomsk.ru 
Acknowledgement: The work was supported by the Russian Science Foundation, Grant16-15-10001. Section devoted to PKA and PKG, is carried out within the framework of state task AAAA-A15-115120910024-0.

Conflict of interest: The authors declare no conflict of interest.

Information about authors:

Voronkov N.S. http://orcid.org/0000-0002-9447-4236

Naryzhnaya N.V. http://orcid.org/0000-0003-2264-1928

Maslov L.N., http://orcid.org/ 0000-0002-6020-1598

Received 21.11.2019

Accepted 16.01.2020

Published 25.02.2020

\section{Введение}

Известно, что адаптация к гипоксии повышает устойчивость сердца к действию ишемии/реперфузии [1-6]. В регуляции толерантности сердца к действию важную роль играют ишемии/реперфузии киназы [7, 8]. Активация одних киназ увеличивает устойчивость сердца к действию ишемии/реперфузии [7, 8], другие киназы, напротив, участвуют в реперфузионном повреждении сердца $[9,10]$. В обзоре анализируются данные о роли киназ в реализации инфаркт-лимитирующего эффекта адаптации к гипоксии (для облегчения восприятия материала ссылки на конкретные сообщения авторов о роли киназ суммированы в таблице).

Протеинкиназа $C$. Известно, что протеинкиназа С (ПКС) принимает участие в кардиопротекторном эффекте ишемического прекондиционирования и посткондиционирования $[7,8]$, поэтому исследователи обратили внимание на роль этого фермента в инфаркт-лимитирующем эффекте адаптации к гипоксии. У детей с пороком сердца и цианозом, а также в эксперименте у новорожденных кроликов, находившихся в условиях гипоксии, обнаружена транслокация киназы ПКСє в клеточные органеллы [11]. У крыс, находящихся длительное время в условиях гипоксии, наблюдается увеличение уровня киназ ПКС, ПКС, ПКС 5 [12]. Установлено, что инфаркт-лимитирующий эффект хронической периодической гипоксии не проявляется после блокады ПКС хелеритрином [13]. Селективный блокатор ПКСठ роттлерин уменьшал, но не устранял инфаркт-лимитирующий эффект хронической периодической гипоксии [13]. Хроническая периодическая гипоксия индуцировала транслокацию ПКС в митохондрии и ядра клеток. Нами установлено, что роттлерин устраняет адаптационное повышение толерантности кардиомиоцитов к действию аноксии/реоксигенации [14]. Эти факты указывают на важную роль ПКСठ в кардиопротекторном эффекте хронической гипоксии. Показано также, что хроническая гипоксия способствует повышению в миокарде уровня активатора
ПКС диацилглицерола [15], возможно он индуцирует активацию ПКС. Вместе с тем, есть данные о том, что увеличение активности ПКСठ может быть результатом окислительного стресса, который наблюдается в условиях хронической периодической гипоксии [16]. Так, было установлено, что ежедневное введение крысам антиоксиданта $\mathrm{N}$-ацетилцистеина устраняет инфаркт-лимитирующий эффект хронической периодической гипоксии и предотвращает транслокацию ПКСठ в клеточные органеллы [16]. Действительно, образование нитротирозина, маркера оксидативного сресса, было повышено в миокарде, особенно в митрохондриях, при хронической гипоксии [17]. Способность активных форм кислорода активировать ПКС является известным фактом [18], который хорошо согласуется с данными исследований, выполненных на адаптированных к хронической периодической гипоксии крысах [16]. Следует отметить, что ПКСठ принимает участие в кардиопротекторном эффекте хронической непрерывной гипоксии [14]. Так установлено, что уровень ПКСठ отрицательно коррелирует с размером инфаркта после адаптации к гипоксии [17]. Хроническая периодическая гипоксия повышает устойчивость кардиомиоцитов к действию аноксии/реоксигенации и снижает $\mathrm{Ca}^{2+}$-перегрузку кардиомиоцитов[19]. Хелеритрин, ингибитор ПКС, устраняет защитные эффекты [19]. Представленные данные убедительно свидетельствуют об участии ПКС в кардиопротекторном эффекте хронической гипоксии.

Вместе с тем, есть данные, что ПКСє также участвует в повышении толерантности сердца к действию ишемии/реперфузии после адаптации к непрерывной гипоксии [20]. Адаптация крыс к гипоксии приводила к повышению толерантности кардиомиоцитов к 25-минутному ингибированию, которое достигалось с помощью $\mathrm{NaCN}$ и 2-дезоксиглюкозы. Было обнаружено, что хроническая гипоксия приводит к усилению экспрессии ПКСє. Селективный ингибитор ПКСє КР- 
1633 устраняет цитопротекторный эффект хронической гипоксии [20]. Возможно, что в кардиопротекторном эффекте ХГ участвуют и другие изоформы ПКС. Так, было обнаружено, что хроническая периодическаяя гипоксия приводит к усилению экспрессии в миокарде киназы ПКС $\alpha$, в том числе ее фосфорилированной формы. [21]. Хроническая непрерывная ги-

Таблица

Влияние хронической гипоксии на экспрессию протеинкиназ в миокарде

\begin{tabular}{|c|c|}
\hline Название киназ & Авторы \\
\hline ПКС $\uparrow, \Pi К С \varepsilon \uparrow, \Pi К С \zeta \uparrow$ & Morel O.E. et al., 2003 [12] \\
\hline ПКСठ $\uparrow$ & Hlavackova M. et al., 2007 [17] \\
\hline$\Pi К С \varepsilon \uparrow$ & Holzerova K. et al., 2015 [20] \\
\hline$\Pi К \mathrm{~K} \alpha \uparrow$ & Micova P. et al., 2016 [21] \\
\hline p-AMPK $\downarrow$ & Xie S. et al., 2016 [23] \\
\hline CaMKII $\gamma \uparrow$, CaMKII $\uparrow \uparrow$ & Zhao P.J. et al., 2008 [24] \\
\hline ERK2 $\uparrow$ & Strnisková M. et al., 2006 [27] \\
\hline $\mathrm{p}-\mathrm{ERK} 1 / 2 \uparrow$ & Milano G. et al., 2010 [28] \\
\hline $\mathrm{p}-\mathrm{ERK} 1 / 2 \uparrow$ & Micova P. et al., 2016 [21] \\
\hline $\mathrm{p}-\mathrm{ERK} 1 / 2 \uparrow$ & Zhang K. et al., 2018 [29] \\
\hline $\mathrm{p}$-Akt $\uparrow$ & Strnisková M. et al., 2006 [27] \\
\hline $\mathrm{p}$-Akt $\uparrow$ & Kolar D. et al., 2017 [32] \\
\hline PI3K $\downarrow$, p-Akt $\downarrow$ & Zhang K. et al., 2018 [29] \\
\hline ПКА нет эффекта & Larsen K.O. et al., 2008 [33] \\
\hline p38 $\downarrow, \mathrm{p}-\mathrm{p} 38 \downarrow$ & Morel S. et al., 2006 [34] \\
\hline p-p38 в ПЖ $\downarrow$, p-p38 в ЛЖ $\uparrow$ & Strnisková M. et al., 2006 [27] \\
\hline p-p38 в ЛЖ $\uparrow$ & Micova P. et al., 2016 [21] \\
\hline $\mathrm{p}-\mathrm{p} 38 \uparrow$ & Quing M. et al., 2007 [35] \\
\hline p-JNK в ЛЖ нет эффекта & Morel S. et al., 2006 [34] \\
\hline JNK и p-JNK в ЛЖ нет эффекта & Strnisková M.et al., 2006 [27] \\
\hline JNK и p-JNK в ПЖ нет эффекта & Strnisková M. et al., 2006 [27] \\
\hline $\mathrm{p}-\mathrm{JNK} \uparrow$ & He S. et al., 2016 [37] \\
\hline $\mathrm{p}-\mathrm{JNK} / \mathrm{JNK} \uparrow$ & Zhao Y.S. et al., 2019 [38] \\
\hline p-GSK3 $\beta$ нет эффекта & McCarthy J. et al., 2011 [41] \\
\hline $\mathrm{HK}-1 \uparrow, \mathrm{HK}-2 \uparrow$ & $\begin{array}{l}\text { Waskova-Arnostova P. et al., } \\
2015 \text { [42] }\end{array}$ \\
\hline $\mathrm{HK}-1 \uparrow, \mathrm{HK}-2 \uparrow$ & Kolar D. et al., 2017 [32] \\
\hline $\mathrm{HK}-1 \uparrow, \mathrm{HK}-2 \uparrow$ & Nedvedova I. et al., 2018 [2] \\
\hline
\end{tabular}

Примечание. ПКС - протеинкиназа С, АМРК - AMP-activated protein kinase, CaMKII - $\mathrm{Ca}^{2+}$-calmodulin kinase II, ERK - extracellular signal-regulated kinase, Akt - Akt-киназа, PI3K - phosphatidylinositol3-kinase, ПКА - протеинкиназа А, p38 - p38-киназа, JNK - c-Jun $\mathrm{N}$-terminal kinase, PKG - протеинкиназа G, GSK3 $\beta$ - glycogen synthase kinase $3 \beta$, НK - hexokinase, ПЖ - правый желудочек, ЛЖ левый желудочек. поксия приводила к усилению транслокации РКСßІІ и РКС в мембраны кардиомиоцитов [22].

Таким образом, по меньшей мере, 2 изоформы ПКС (ПКС $и$ и ПКС $)$ участвуют в кардиопротекторном эффекте хронической гипоксии (табл.).

Киназа АМРК. АТФ-активируемая протеинкиназа AMPK (AMP-activated protein kinase) играет важную роль в реализации феномена пре- и посткондиционирования [7]. По всей видимости, АМРК не играет существенной роли в кардиопротекторном эффекте адаптации к гипоксии, поскольку у крыс, подвергнутых хронической периодической гипоксии, отмечается снижение уровня активированной АМРК в миокарде [23]

Киназа СаМКII. Известно, что активация киназы CaMKII $\left(\mathrm{Ca}^{2+}\right.$-calmodulin kinase II) усугубляет повреждение сердца, вызванное ишемией/перфузией [10], что дало основание предполагать, что её активность в миокарде снижается при адаптации к гипоксии. Однако было обнаружено, что экспрессия мРНК, кодирующей кальмодулин, СаМКII $\gamma$, СаМКІІб в миокарде крыс после воздействия хронической гипоксии усиливается [24]. Усиление экспрессии СаМКII после воздействия хронической гипоксии отмечали другие исследователи [25]. Получены данные, что повышенная экспрессия СаМКII может препятствовать повреждению кардиомиоцитов при $\mathrm{Ca}^{2+}$-парадоксе [26], но может ли СаМКII обеспечивать инфаркт-лимитирующий эффект хронической гипоксии - неизвестно (табл.).

Киназы ERK и MEK. Киназы ERK (extracellular signal-regulated kinase) и МЕК (mitogen-activated protein kinase) играют важную роль в пре- и посткондиционировании сердца [7], поэтому были основания полагать, что они могут участвовать в инфаркт-лимитирующем эффекте хронической гипоксии. Установлено, что хроническая периодическая гипоксия приводит к увеличению экспрессии ERK2 в миокарде крыс [27] и вызывает увеличение в миокарде уровня фосфорилированной ERK1/2 (p-ERK1/2) [28]. Ингибиторы MEK1/2 U0126 и PD-98059 устраняли инфаркт-лимитирующий эффект хронической периодической гипоксии [28]. Увеличение количества p-ERK1/2 в миокарде крыс после хронической периодической гипоксии отмечают и другие исследователи $[21,29]$. Представленные данные указывают на то, что ERK1/2 и MEK1/2 участвуют в кардиопротекторном эффекте периодической гипоксии (табл.).

Киназы PI3К и Akt. Киназы PI3K (phosphatidylinositol3-kinase) и Akt принимают участие в пре- и посткондиционировании сердца [7], поэтому можно было предположить, что они участвуют в кардиопротекторном эффекте хронической гипоксии. Показано, что хрони- 
ческая периодическая гипоксия вызывает увеличение экспрессии p-Akt в левом желудочке сердца крыс [27]. Установлено, что ингибитор PI3K LY294002 устраняет инфаркт-лимитирующий эффект периодической гипоксии [30]. Хроническая умеренная гипоксия вызывает увеличение уровня p-Akt в кардиомиобластах H9c2 [31]. В исследовании, выполненном на изолированных перфузируемых сердцах крыс, подвергнутых ишемии/ реперфузии, было показано, что инфаркт-лимитирующий эффект хронической периодической гипоксии связан с активацией PI3K [28]. Кроме того, показано, что хроническая непрерывная гипоксия вызывает увеличение уровня p-Akt в миокарде крыс [32]. Вместе с тем, по данным некоторых авторов [29], хроническая периодическая гипоксия вызывает снижение в миокарде крыс уровня PI3K и p-Akt. Нам также не удалось подтвердить участие РІ3К в инфаркт-лимитирующем эффекте хронической непрерывной гипоксии [1]. Нами было установлено, что блокада РІ3К вортманнином не влияет на повышение толерантности изолированных кардиомиоцитов к действию аноксии/реоксигенации у адаптированных к хронической непрерывной гипоксии крыс [14]. Таким образом, вопрос о роли РІ3К и Akt в кардиопротекторном эффекте хронической непрерывной гипоксии является спорным (табл.)

Киназа ПКА. Протеинкиназа А (ПКА) является цАМФ-зависимой киназой, которая по мнению некоторых авторов [7], принимает участие в кардиопротекторном эффекте пре- и посткондиционирования. У мышей, подвергнутых воздействию хронической непрерывной гипоксии не удалось обнаружить изменения количества изоформ ПКА [33]. Однако это пока единственная работа, в которой оценивали влияние длительной гипоксии на уровень ПКА, поэтому делать вывод роли ПКА в кардиопротекторном эффекте адаптации к гипоксии пока рано.

Киназа р38. Киназа 38 также участвует в пре- и посткондиционировании [7]. Установлено, что хроническая периодическая гипоксия вызывает снижение уровня киназы р38 и р-р38 в миокарде [34]. Хроническая непрерывная гипоксия не оказывала подобного эффекта [34]. В то же время, согласно данным М Strnisková и др. [27], при хронической периодической гипоксии уровень p-p38 в правом желудочке снижается, а в левом желудочке сердца повышается, уровень общей р38 не изменяется. Повышение уровня p-p38 в миокарде левого желудочка после хронической периодической гипоксии было отмечено в более поздней работе того же коллектива исследователей [21]. Показано, что уровень p-p38 увеличен в миокарде у детей с пороками сердца и цианозом, но не у больных с поро- ками сердца без цианоза [35]. Установлено, что блокирование р38 ингибитором SB203580 устраняет кардиопротекторный эффект хронической непрерывной гипоксии [11]. Представленные данные говорят о повышении уровня p-p38 в миокарде левого желудочка при хронической периодической гипоксии, что способствует повышению толерантности сердца к действию ишемии/реперфузии. Вместе с тем, следует отметить, что позитивная роль р38 в кардиопротекторном эффекте хронической гипоксии показана только в одной статье [11] (табл.).

Киназа JNK. Принято считать, что JNK (с-Jun Nterminal kinase) играет негативную роль в регуляции толерантности сердца к действию ишемии/реперфузии [9]. Вместе с тем, есть данные о том, что этот фермент участвует в кардиопротекторном эффекте дистантного прекондиционирования [36]. Установлено, что куркумин, ингибитор JNK, устраняет кардиопротекторный эффект хронической непрерывной гипоксии у кроликов [11]. При хронической периодической гипоксии не удалось обнаружить увеличение уровня p-JNK в левом желудочке сердца крыс [34]. В то же время, другим исследователям не удалось обнаружить изменения уровня общей JNK и p-JNK в правом и левом желудочках сердца адаптированных к хронической периодической гипоксии крыс [27]. Пребывание кардиомиобластов Н9С2 в среде, содержащей $1 \% \mathrm{O}_{2}$, в течение 72 ч способствовало увеличению уровня p-JNK [37]. Установлено, что хроническая периодическая гипоксия приводит к увеличению соотношения р-JNK/ JNK в миокарде [38]. Представленные данные свидетельствуют о том, что хроническая гипоксия может приводить к увеличению уровня активной р-JNK в миокарде. Вместе с тем, данные об участии этой киназы в кардиопротекторном эффекте адаптации ограничены пока одной статьёй [11], поэтому вопрос о роли JNK в защитном эффекте хронической периодической гипоксии остаётся открытым (табл.).

Kиназа mTOR. Есть данные о том, что рапамицин, ингибитор mTOR (mammalian target of rapamycin), устраняет кардиопротекторный эффект ишемического прекондиционирования [39]. Следовательно, были основания предполагать, что mTOR может принимать участие в кардиопротекторном эффекте хронической гипоксии. Установлено, что рапамицин устраняет гипертрофию сердца, вызванную хронической периодической гипоксией [23]. Эти данные указывают на то, что $\mathrm{mTOR}$ при хронической периодической гипоксии активируется. Вместе с тем, они не дают ответа на вопрос о роли mTOR в инфаркт-лимитирующем эффекте хронической гипоксии. 
Киназа PKG. Известно, что PKG (cGMP-dependent protein kinase $\mathrm{G}$ ) участвует в кардиопротекторном эффекте пре- и посткондиционирования [7], поэтому были основания предполагать, что эта киназа участвует в инфаркт-лимитирующем эффекте хронической гипоксии. Было установлено, что хроническая гипобарическая гипоксия вызывает увеличение в миокарде уровня цГМФ, активатора PKG [25]. Пока остаётся неизвестным, ведет ли увеличение содержания цГМФ в миокарде к повышению активности PKG. Неизвестно, какова роль этой киназы в инфаркт-лимитирующем эффекте хронической гипоксии.

Киназа GSK3ß. Известно, что фосфорилирование GSK $3 \beta$ (glycogen synthase kinase $3 \beta$ ) способствует инактивации этой киназы и повышению устойчивости сердца к действию ишемии/реперфузии [40]. Установлено, что хроническая гипоксия не влияет на уровень p-GSK3ß в миокарде мышей [41]. Следовательно, GSK3 $\beta$ не играет существенной роли в инфаркт-лимитирующем эффекте хронической гипоксии. Вместе с тем, это пока единственное исследование, в котором оценивали роль GSK3ß в кардиопротекторном эффекте адаптации к гипоксии [41] (табл.).

Гексокиназа 2 (HK-2, hexokinase 2). Полагают, что связывание НK-2 с митохондриями предупреждает апоптоз кардиомиоцитов [7]. Установлено, что хроническая периодическая гипоксия вызывает транслокацию гексокиназы в митохондрии [42]. Кроме того, было установлено, что хроническая периодическая гипоксия вызывает увеличение экспрессии НК-1 и НК-2 в миокарде [42]. Хроническая непрерывная гипоксия также повышала экспрессию НК-1 и НК-2 в миокарде, усиливала ассоциацию НК-2 с митохондриями [32]. Аналогичные эффекты хронической непрерывной гипоксии обнаружены у крыс линии SHR [2] (табл.).

Rho-киназа (ROCK, Rho-associated protein kinase). Известно, что Rho-киназа участвует в апоптозе кардиомиоцитов [43], а её ингибирование способствует уменьшению размера инфаркта при ишемии/реперфузии сердца [44]. Можно было ожидать, что экспрессия Rho-киназы будет снижаться в миокарде крыс при адаптации. Однако оказалось, что гипертрофия правого желудочка сердца при хронической гипоксии связана с активацией Rho-киназы [45]. Показано, что при хронической периодической гипоксии гипертрофия миокарда левого желудочка также связана активацией Rho-киназы [46]. Имеет ли указанная киназа отношение к кардиопротекторному эффекту хронической гипоксии пока неясно.

Таким образом, анализ данных о роли киназ в реализации кардиопротекторного эффекта адаптации к гипоксии показал, что хроническая гипоксия приводит к усилению экспрессии в миокарде следующих ки-

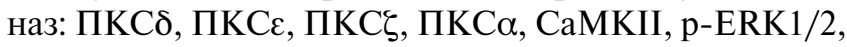
p-p38, p-Akt, HK-1, НK-2. Адаптация к гипоксии усиливает ассоциацию НК-2 с митохондриями и вызывает транслокацию ПКС $\delta$, РКС $\beta І І$ и РКС в мембраны кардиомиоцитов. В исследовании, выполненном на адаптированных к гипоксии животных, не удалось обнаружить усиления экспрессии киназ: ПКА, p-GSK3ß, AMPK и JNK. Доказано, что ПКСס, ПКС, ERK1/2, MEK $1 / 2$ участвуют в кардиопротекторном эффекте хронической гипоксии. Роль киназ JNK, PKG, Rhoкиназы, mTOR и p38 в кардиопротекторном эффекте адаптации к гипоксии требует дальнейшего изучения.

\section{Участие авторов:}

Концепция и дизайн исследования - Н.С. Воронков, Н.В. Нарыжная, Л.Н. Маслов

Написание текста, редактирование - Н.С. Воронков, Н.В. Нарыжная, Л.Н. Маслов

\section{Литература \\ (п.п. 1-13; 15-46 cM. References)}

14. Нарыжная Н.В., Маслов Л.Н., Халиулин И.Г., Пей Ж.-М., Жанг И., Цепокина А.В. и др. Адаптация с помощью хронической непрерывной нормобарической гипоксии увеличивает толерантность кардиомиоцитов крыс к аноксии-реоксигенации: рольпротеинкиназ. Российский физиологический журнал им. И.М. Сеченова. 2016; 102(12): 1462-71.

\section{References}

1. Tsibulnikov S.Y., Maslov L.N., Naryzhnaya N.V., Ma H., Lishmanov Y.B., Oeltgen P.R., Garlid K. Role of protein kinase C, PI3 kinase, tyrosine kinases, NO-synthase, KATP channels and MPT pore in the signaling pathway of the cardioprotective effect of chronic continuous hypoxia. General Physiology Biophysics. 2018; 37(5): 537-47.

2. Nedvedova I., Kolar D., Elsnicova B., Hornikova D., Novotny J., Kalous M., et al. Mitochondrial genome modulates myocardial Akt/ Glut/HK salvage pathway in spontaneously hypertensive rats adapted to chronic hypoxia. Physiological Genomics. 2018; 50(7): 532-41.

3. Kolar F., Ostádal B. Molecular mechanisms of cardiac protection by adaptation to chronic hypoxia. Physiological Research. 2004; 53(1): S3-S13.

4. Gu S., Hua H., Guo X., Jia Z., Zhang Y., Maslov L.N., et al. PGC$1 \alpha$ Participates in the protective effect of chronic intermittent hypobaric hypoxia on cardiomyocytes. Cell Physiology and Biochemistry. 2018; 50(5): 1891-902.

5. Meerson F.Z., Ustinova E.E., Manukhina E.B. Prevention of cardiac arrhythmias by adaptation to hypoxia: regulatory mechanisms and cardiotropic effect. Biomedica Biochimica Acta. 1989; 48(2-3): S83-S8.

6. Estrada J.A., Williams A.G., Sun J., Gonzalez L., Downey H.F., Caffrey J.L., Mallet R.T. $\delta$-Opioid receptor (DOR) signaling and reactive oxygen species (ROS) mediate intermittent hypoxia induced protection of canine myocardium. Basic Research in Cardiology. 2016; 111(2): 17. 
7. Heusch G. Molecular basis of cardioprotection: signal transduction in ischemic pre-, post-, and remote conditioning. Circulation Research. 2015; 116(4): 674-99.

8. Yellon D.M., Downey J.M. Preconditioning the myocardium: from cellular physiology to clinical cardiology. Physiological Reviews. 2003; 83(4): 1113-51.

9. Milano G., Morel S., Bonny C., Samaja M., von Segesser L.K., Nicod P., Vassalli G. A peptide inhibitor of c-Jun NH2-terminal kinase reduces myocardial ischemia-reperfusion injury and infarct size in vivo. American Journal of Physiology - Heart and Circulatory Physiology. 2007; 292(4): H1828-H35.

10. Ling H., Gray C.B., Zambon A.C., Grimm M., Gu Y., Dalton N., et al. CaMKIIס mediates myocardial ischemia/reperfusion injury through nuclear factor-xB. Circulation Research. 2013; 112(6): 935-44.

11. Rafiee P., Shi Y., Kong X., Pritchard K.A., Tweddell J.S., Litwin S.B., et al. Activation of protein kinases in chronically hypoxic infant human and rabbit hearts: role in cardioprotection. Circulation. 2002; 106(2): 239-45.

12. Morel O.E., Buvry A., Le Corvoisier P., Tual L., Favret F., LeónVelarde F., et al. Effects of nifedipine-induced pulmonary vasodilatation on cardiac receptors and protein kinase $\mathrm{C}$ isoforms in the chronically hypoxic rat. Pflügers Archiv. 2003; 446(3): 356-64.

13. Neckar J., Marková I., Novák F., Nováková O., Szárszoi O., Ost’ádal B., Kolár F. Increased expression and altered subcellular distribution of PKC- $\delta$ in chronically hypoxic rat myocardium: involvement in cardioprotection. American Journal of Physiology-Heart and Circulatory Physiology. 2005; 288(4): H1566-H72.

14. Naryzhnaya N.V., Maslov L.N., Khaliulin I.G., Pei J.M., Zhang Y., Tsepokina A.V., et al. Chronic continuous normobaric hypoxia augments cell tolerance to anoxia/reoxygenation: the role of protein kinases. Rossiyskiy fiziologicheskiy zhurnal imeni I.M. Sechenova. 2016; 102(12): 1462-71. (in Russian)

15. El Alwani M., Usta J., Nemer G., El Sabban M., Nasser M., Bitar $\mathrm{H}$., et al. Regulation of the sphingolipid signaling pathways in the growing and hypoxic rat heart. Prostaglandins \& Other Lipid Mediators. 2005; 78(1-4): 249-63.

16. Kolar F., Jezková J., Balková P., Breh J., Neckár J., Novák F., et al. Role of oxidative stress in PKC- $\delta$ upregulation and cardioprotection induced by chronic intermittent hypoxia. American Journal of Physiology-Heart and Circulatory Physiology. 2007; 292(1): H224-H30.

17. Hlaváčková M., Neckár J., Jezková J., Balková P., Stanková B., Nováková O., et al. Dietary polyunsaturated fatty acids alter myocardial protein kinase $\mathrm{C}$ expression and affect cardioprotection induced by chronic hypoxia. Experimental Biology and Medicine (Maywood). 2007; 232(6): 823-32.

18. Krylatov A.V., Maslov L.N., Voronkov N.S., Boshchenko A.A., Popov S.V., Gomez L., et al. Reactive oxygen species as intracellular signaling molecules in the cardiovascular system. Current Cardiology Reviews. 2018; 14(4): 290-300.

19. Ma H.J., Li Q., Ma H.J., Guan Y., Shi M., Yang J., Li D.P., Zhang Y. Chronic intermittent hypobaric hypoxia ameliorates ischemia/reperfusion-induced calcium overload in heart via $\mathrm{Na}^{+} / \mathrm{Ca}^{2+}$ exchanger in developing rats. Cell Physiology and Biochemistry. 2014; 34(2): 313-24.

20. Holzerova K., Hlaváčková M., Žurmanová J., Borchert G., Neckář J., Kolár F., et al. Involvement of PKC $\varepsilon$ in cardioprotection induced by adaptation to chronic continuous hypoxia. Physiological Research. 2015; 64(2): 191-201.

21. Micova P., Hahnova K., Hlavackova M., Elsnicova B., Chytilova A., Holzerova K., et al. Chronic intermittent hypoxia affects the cyto- solic phospholipase A2 $\alpha$ /cyclooxygenase 2 pathway via $\beta 2$ adrenoceptor-mediated ERK/p38 stimulation. Molecular and Cellular Biochemistry. 2016; 423(1-2): 151-63.

22. Zeng C., Liang B., Jiang R., Shi Y., Du Y. Protein kinase C isozyme expression in right ventricular hypertrophy induced by pulmonary hypertension in chronically hypoxic rats. Molecular Medicine Reports. 2017; 16(4): 3833-40.

23. Xie S., Deng Y., Pan Y.Y., Ren J., Jin M., Wang Y., et al. Chronic intermittent hypoxia induces cardiac hypertrophy by impairing autophagy through the adenosine 5'-monophosphate-activated protein kinase pathway. Archives of Biochemistry and Biophysics. 2016; 606: $41-52$.

24. Zhao P.J., Pan J., Li F., Sun K. Effects of chronic hypoxia on the expression of calmodulin and calcicum/calmodulin-dependent protein kinase II and the calcium activity in myocardial cells in young rats. Zhongguo Dang Dai Er Ke Za Zhi. 2008; 10(3): 381-5.

25. Nehra S., Bhardwaj V., Kar S., Saraswat D. Chronic hypobaric hypoxia induces right ventricular hypertrophy and apoptosis in rats: therapeutic potential of nanocurcumin in improving adaptation. High Altitude Medicine \& Biology. 2016; 17(4): 342-52.

26. Xie Y., Zhu W.Z., Zhu Y., Chen L., Zhou Z.N., Yang H.T. Intermittent high altitude hypoxia protects the heart against lethal $\mathrm{Ca} 2+$ overload injury. Life Sciences. 2004; 76(5): 559-772.

27. Strnisková M., Ravingerová T., Neckár J., Kolár F., Pastoreková S., Barancík M. Changes in the expression and/or activation of regulatory proteins in rat hearts adapted to chronic hypoxia. General Physiology and Biophysics. 2006; 25(1): 25-41.

28. Milano G., von Segesser L.K., Morel S., Joncic A., Bianciardi P., Vassalli G., Samaja M. Phosphorylation of phosphatidylinositol-3-kinaseprotein kinase B and extracellular signal-regulated kinases $1 / 2$ mediate reoxygenation-induced cardioprotection during hypoxia. Experimental Biology and Medicine (Maywood). 2010; 235(3): 401-10

29. Zhang K., Ma Z., Wang W., Liu R., Zhang Y., Yuan M., Li G. Beneficial effects of tolvaptan on atrial remodeling induced by chronic intermittent hypoxia in rats. Cardiovascular Therapeutics. 2018; 36(6): e12466.

30. Ravingerová T., Matejíková J., Neckár J., Andelová E., Kolár F. Differential role of PI3K/Akt pathway in the infarct size limitation and antiarrhythmic protection in the rat heart. Molecular and Cellular Biochemistry. 2007; 297(1-2): 111-20.

31. Jia W., Jian Z., Li J., Luo L., Zhao L., Zhou Y., et al. Upregulated ATF6 contributes to chronic intermittent hypoxia-afforded protection against myocardial ischemia/reperfusion injury. International Journal of Molecular Medicine. 2016; 37(5): 1199-208.

32. Kolar D., Gresikova M., Waskova-Arnostova P., Elsnicova B., Kohutova J., Hornikova D., et al. Adaptation to chronic continuous hypoxia potentiates Akt/HK2 anti-apoptotic pathway during brief myocardial ischemia/reperfusion insult. Molecular and Cellular Biochemistry. 2017; 432(1-2): 99-108.

33. Larsen K.O., Lygren B., Sjaastad I., Krobert K.A., Arnkvaern K., Florholmen G., et al. Diastolic dysfunction in alveolar hypoxia: a role for interleukin-18-mediated increase in protein phosphatase $2 \mathrm{~A}$. Cardiovascular Research. 2008; 80(1): 47-54.

34. Morel S., Milano G., Ludunge K.M., Corno A.F., Samaja M., Fleury S., et al. Brief reoxygenation episodes during chronic hypoxia enhance posthypoxic recovery of LV function: role of mitogen-activated protein kinase signaling pathways. Basic Research in Cardiology. 2006; 101(4): 336-45.

35. Quing M., Görlach A., Schumacher K., Wöltje M., VazquezJimenez J.F., Hess J., Seghaye M.C. The hypoxia-inducible factor 
HIF-1 promotes intramyocardial expression of VEGF in infants with congenital cardiac defects. Basic Research in Cardiology. 2007; 102(3): 224-32.

36. Heidbreder M., Naumann A., Tempel K., Dominiak P., Dendorfer A. Remote vs. ischemic preconditioning: the differential role of mitogen-activated protein kinase pathways. Cardiovascular Research. 2008; 78(1): 108-15.

37. He S., Liu S., Wu X., Xin M., Ding S., Xin D., et al. Protective role of downregulated MLK3 in myocardial adaptation to chronic hypoxia. Journal of physiology and biochemistry. 2016; 73(3): 371-80.

38. Zhao Y.S., An J.R., Yang S., Guan P., Yu F.Y., Li W., et al. Hydrogen and oxygen mixture to improve cardiac dysfunction and myocardial pathological changes induced by intermittent hypoxia in rats. Oxidative Medicine and Cellular Longevity. 2019; 2019: 7415212.

39. Wagner C., Tillack D., Simonis G., Strasser R.H., Weinbrenner C. Ischemic post-conditioning reduces infarct size of the in vivo rat heart: role of PI3-K, mTOR, GSK-3beta, and apoptosis. Molecular and Cellular Biochemistry. 2010; 339(1-2): 135-47.

40. Miura T., Miki T. GSK-3 $\beta$, a therapeutic target for cardiomyocyte protection. Circ. J. 2009; 73(7): 1184-92.

41. McCarthy J., Lochner A., Opie L.H., Sack M.N., Essop M.F. PKCع promotes cardiac mitochondrial and metabolic adaptation to chron- ic hypobaric hypoxia by GSK3ß inhibition. Journal of Cellular Physiology. 2011; 226(9): 2457-68.

42. Waskova-Arnostova P., Elsnicova B., Kasparova D., Hornikova D., Kolar F., Novotny J., Zurmanova J. Cardioprotective adaptation of rats to intermittent hypobaric hypoxia is accompanied by the increased association of hexokinase with mitochondria. Journal of Applied Physiology. 2015; 119(12): 1487-93.

43. Zhang J., Li X.X., Bian H.J., Liu X.B., Ji X.P., Zhang Y. Inhibition of the activity of Rho-kinase reduces cardiomyocyte apoptosis in heart ischemia/reperfusion via suppressing JNK-mediated AIF translocation. Clinica Chimica Acta. 2009; 401(1-2): 76-80.

44. Bao W., Hu E., Tao L., Boyce R., Mirabile R., Thudium D.T., et al. Inhibition of Rho-kinase protects the heart against ischemia/reperfusion injury. Cardiovascular Research. 2004; 61(3): 548-58.

45. Gosal K., Dunlop K., Dhaliwal R., Ivanovska J., Kantores C., Desjardins J.F., et al. Rho kinase mediates right ventricular systolic dysfunction in rats with chronic neonatal pulmonary hypertension. American Journal of Respiratory Cell and Molecular Biology. 2015; 52(6):717-27.

46. Wang Z.H., Zhu D., Xie S., Deng Y., Pan Y., Ren J., Liu H.G. Inhibition of Rho-kinase attenuates left ventricular remodeling caused by chronic intermittent hypoxia in rats via suppressing myocardial inflammation and apoptosis. Journal of Cardiovascular Pharmacology. 2017; 70(2): 102-09.

Сведения об авторах:

Воронков Никита Сергеевич, лаборант-исследователь лаб. экспериментальной кардиологии, НИИ кардиологии Томского НИМЦ, e-mail: niks.voronkov@gmail.com;

Нарыжная Наталия Владимировна, доктор мед. наук, вед. науч. сотр. лаб. экспериментальной кардиологии, НИИ кардиологии, Томского НИМЦ, e-mail: natalynar@yandex.ru;

Маслов Леонид Николаевиц, доктор мед.н., проф. руководитель лаб. экспериментальной кардиологии, НИИ кардиологии Томского НИМЦ; e-mail: maslov@cardio-tomsk.ru 